\title{
HOW A COLD SITZ BATH VERSUS INFRARED THERAPY CAN REMOVE THE PAIN OF POSTPARTUM PERINEAL WOUNDS?
}

\author{
Bina Melvia Girsang*1, Eqlima Elfira² \\ 1. Department of Maternity and Child Nursing, Faculty of Nursing, Universitas Sumatera Utara, Indonesia \\ 2. Department of Medical Surgical Nursing, Faculty of Nursing, Universitas Sumatera Utara, Indonesia
}

\section{Article Information}

Received: 19 July 2019

Revised: 16 October 2019

Accepted: 27 January 2021

\section{*Corresponding Author}

Bina Melvia Girsang

binamelvia@usu.ac.id

\section{DOI}

10.20884/1.jks.2021.16.1.1124

\begin{abstract}
Women who suffer perineal trauma in spontaneous labor experience pain and edema as the most common problems on the first day after delivery. Impaired mobility and a limited ability to carry out daily activities will affect the mother-baby bond. The study of the cold sitz bath intervention and infrared treatment aims to determine how these interventions can overcome the pain of perineal wounds in postpartum mothers. A quasi-experimental design was used to assess both interventions for treating pain in perineal trauma at the Madina Clinic and Sundari Hospital. The sample consisted of 40 mothers, 20 in the cold sitz bath (intervention group) and 20 in the infrared therapy (control group). The pain was measured using a numerical scale from day one to day three of the postpartum period, and then the data were analyzed using the paired t-test statistical test. The results of this study revealed that the cold sitz bath hydrotherapy had a significant effect in reducing pain $(p=0.004)$ and infrared therapy (0.008). Although the infrared treatment did not significantly reduce the pain level on the third day of the postpartum period, several other factors could contribute to the significant differences in pain intensity reduction, such as comfort, convenience, and the intervention's economic value.
\end{abstract}

Keywords: Cold; hydrotherapy; infrared; pain; perineal trauma; sitz bath

\section{INTRODUCTION}

The maternal mortality rate in the world is mostly led by developing countries as much as 99 percent. Nigeria has a perineal wound infection prevalence rate of 23 percent (Sule \& Shittu, 2003). In comparison, other studies have reported 2 percent in spontaneous labor (Larsson et al., 1991). The geographic health survey results in Indonesia in 2010 obtained maternal mortality ratio (MMR) data of 263 per 100,000 live births (Kemenkes RI, 2013). Complications including puerperal infection, improper treatment of perineal wounds, and bleeding (Hernawati, 2011). During pregnancy, childbirth, and the postpartum period that is not immediately addressed are the leading causes of maternal death (De Bernis et al., 2003). During postpartum recovery, mothers need proper perineal wound care to prevent infection, reducing pain in the perineal wounds. Perineal wounds can cause maternal discomfort that further can affect the mental condition and may lead to mothers experiencing "baby blues' or postpartum depression (De Bernis et al., 2003; Yang et al., 2017).

Bathing perineal wounds with a sitz bath and having infrared therapy are both non-pharmacological treatments. Administration of a cold compress, twice a day after each bath, can relieve the pain experienced due to perineal wounds in the first 24 hours postpartum (Ramler \& Roberts, 1986). The cold soaking process should be as comfortable as possible for 10-20 minutes (Geytenbeek, 2002). Meanwhile, infrared therapy is recommended to reduce pain through monochromatic effects emitted to improve the circulation to the perineal wound area.

This research was conducted by observing how a sitz bath intervention and infrared therapy can reduce perineal wounds' pain. These interventions can provide a sense of comfort in the early postpartum period (Enkin et al., 2001; Jacob et al., 2007; Sleep et al., 1991). The results of wound 
repair using monochromatic infrared therapy are significant in reducing pain (Horwitz et al., 1999). This wound healing therapy uses monochromatic 890 nanometers $(\mathrm{nm})$ infrared energy. The wound is irradiated using infrared, which results in the damage shrinking and closing after using monochromatic infrared energy. This method is possible because of an increase in local nitric oxide concentration. Increased nitric oxide correlates with vasodilation and anabolic responses (Dewi \& Ayuningtyas, 2015; Horwitz et al., 1999).

\section{METHOD}

\section{Study design}

This study is a comparative study design to assess the effectiveness of cold water bath intervention versus infrared radiation therapy in removing the pain of postpartum mothers' perineal wonds using a quasi-experimental pretestpostest method.

\section{Participant}

The sampling technique was done using purposive sampling, where 40 postnatal mothers on postpartum days 1,2 , and 3 , who had normal labor with grade 2 perineal injuries were selected. There were 20 mothers in group 1 (cold sitz bath), which was performed at the Madina Clinic and home, while there were 20 mothers in group 2 (infrared radiation), performed at Sundari Hospital, Medan at home.

\section{RESULT}

This study revealed several results, including univariate data and bivariate data. Univariate data, including age, religion, ethnicity, and educators, are presented in Table 1.

Table 1. Frequency distribution, mean and standard deviation of postpartum maternal characteristics

\begin{tabular}{|c|c|c|c|c|}
\hline \multirow{2}{*}{ Variable } & \multicolumn{2}{|c|}{ Group 1 (Hydrotherapy cold sitz bath) } & \multicolumn{2}{|c|}{ Group 2 (Infrared therapy) } \\
\hline & Frequency & Percentage(\%) & Frequency & Percentage (\%) \\
\hline \multicolumn{5}{|l|}{ Age (years old) } \\
\hline $20-25$ & 3 & 15 & 7 & 35 \\
\hline $26-31$ & 9 & 45 & 5 & 25 \\
\hline $31-35$ & 5 & 25 & 7 & 35 \\
\hline$>35$ & 3 & 15 & 1 & 5 \\
\hline \multicolumn{5}{|l|}{ Religion } \\
\hline Moslem & 19 & 95 & 17 & 85 \\
\hline Christian & 1 & 5 & 3 & 15 \\
\hline \multicolumn{5}{|l|}{ Ethnicity } \\
\hline Bataknese & 4 & 20 & 8 & 40 \\
\hline Malay & 1 & 5 & 0 & 0 \\
\hline Minang & 11 & 55 & 1 & 5 \\
\hline Java & 4 & 20 & 10 & 50 \\
\hline Nias & 0 & 0 & 1 & 5 \\
\hline \multicolumn{5}{|l|}{ Education } \\
\hline Primary & 1 & 5 & 1 & 5 \\
\hline Junior high school & 6 & 30 & 15 & 75 \\
\hline Senior high school & 12 & 60 & 4 & 20 \\
\hline College & 1 & 5 & 0 & 0 \\
\hline \multicolumn{5}{|l|}{ Occupation } \\
\hline Entrepreneur & 1 & 5 & 0 & 0 \\
\hline Private employees & 0 & 0 & 1 & 5 \\
\hline Full time housewife & 19 & 95 & 19 & 95 \\
\hline \multicolumn{5}{|l|}{ Parity } \\
\hline Primigravida & 4 & 20 & 3 & 25 \\
\hline Secundigravida & 6 & 30 & 5 & 15 \\
\hline Multigravida & 10 & 50 & 12 & 60 \\
\hline
\end{tabular}

\section{Instrument}

This research was conducted with an instrument pain assessment tool. The pain assessment is measured using a numeric rating scale ranging from the first day to the third day of the postpartum period.

\section{Intervention}

Within this study, cold sitz bath hydrotherapy refers to the procedure of soaking the postnatal mothers' hips and buttocks with perineal wounds in a basin filled with $1 / 4$ parts of cold water (temperature $12^{\circ} \mathrm{C}-14^{\circ} \mathrm{C}$ ) for 10 minutes. This procedure is carried out twice a day for three consecutive days from the puerperal day 1 to 3 . As for infrared radiation therapy, it refers to the exposure of the perineal wounds to infrared radiation for 10 minutes with a distance of $50 \mathrm{~cm}$ from the perineum wound, twice a day for three consecutive days after birth.

\section{Data analysis}

The differences in pain levels for three consecutive days were analyzed using the paired t-test statistical test.

\section{Ethical Consideration}

Administrative approvals and ethical permits have been obtained from nursing institutions that issue ethics approval letters Number 1724 / IV / SP / 2019. Written consent was obtained after explaining the intervention undertaken by the researcher. The principle of confidentiality and anonymity was presented to the research subjects and guaranteed by the researchers. 
The majority of postpartum mothers in group 1 (Sitz bath hydrotherapy) were $26-31$ years old $(45 \%)$, while in group 2 (infrared therapy), they were equally distributed between the $31-35$ and $20-25$ years old age groups $(35 \%$ in each age category). Both groups are predominantly Muslim, with most Mining (55\%) in group 1 and Javanese (50\%) in group 2.
The final education level is mostly senior high school $(60 \%)$ in group 1 and junior high school $(75 \%)$ in group 2 . Postpartum mothers were mostly housewives in both groups $(95 \%)$, with the majority of the parity was multigravida $(50 \%$ in group 1 and $60 \%$ in group 2, respectively).

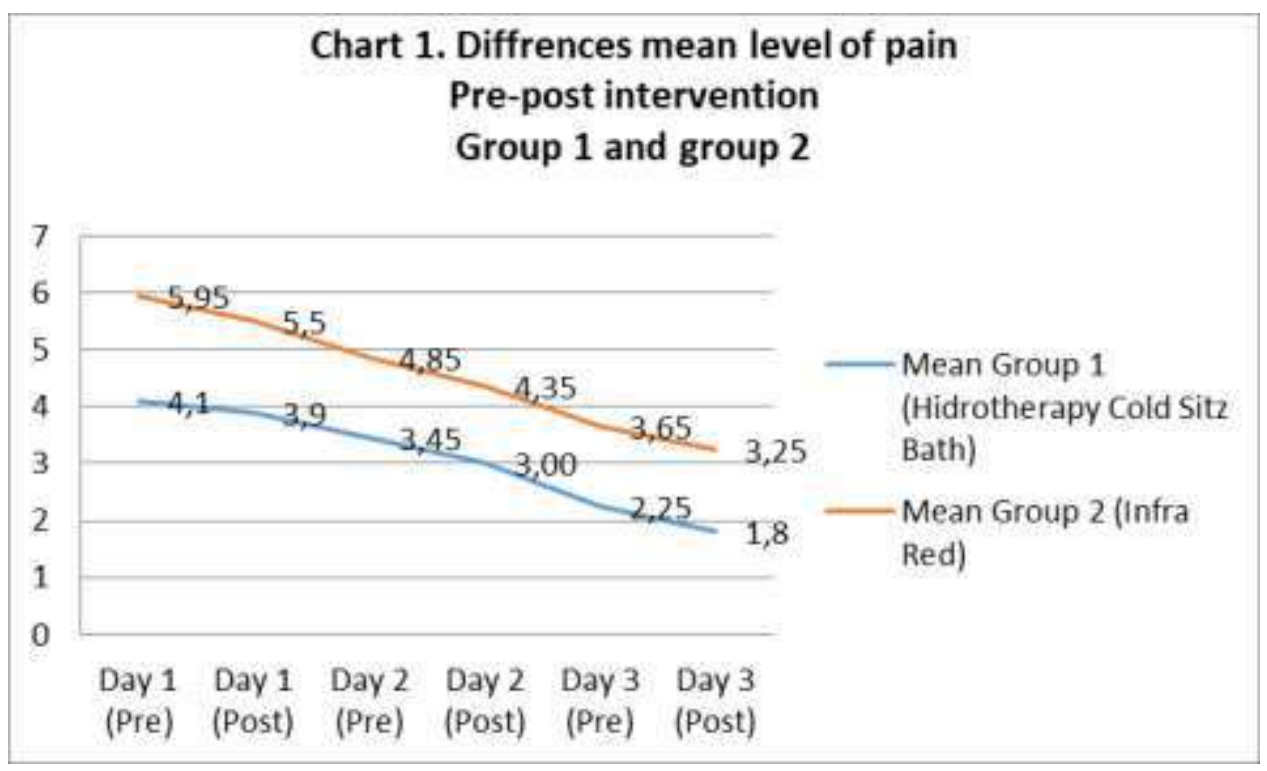

Table 2. Comparison of pre and post pain level for three consecutive days in group 1 and group 2

\begin{tabular}{|c|c|c|c|c|}
\hline Pre-post intervention & Groups & Mean \pm SD & t-Test & $\mathbf{P}$ \\
\hline \multirow[t]{2}{*}{ Pre-post intervention day 1} & Group 1 (Sitz bath) & $\begin{array}{l}4.10 \pm 1.861 \\
3.90 \pm 1.832\end{array}$ & 2.179 & 0.042 \\
\hline & Group 2 (Infrared) & $\begin{array}{l}5.95 \pm 2.188 \\
5.50 \pm 1.906\end{array}$ & 2.131 & 0.046 \\
\hline \multirow[t]{2}{*}{ Pre-post intervention day 2} & Group 1 (Sitz bath) & $\begin{array}{l}3.45 \pm 1.605 \\
3.00 \pm 1.376\end{array}$ & 3.943 & 0.001 \\
\hline & Group 2 (Infrared) & $\begin{array}{l}4.85 \pm 1.981 \\
4.35 \pm 1.785\end{array}$ & 4.359 & 0.000 \\
\hline \multirow[t]{2}{*}{ Pre-post intervention day 3} & Group 1 (Sitz bath) & $\begin{array}{l}2.25 \pm 1.164 \\
1.80 \pm 1.056\end{array}$ & 3.327 & 0.004 \\
\hline & Group 2 (Infrared) & $\begin{array}{l}3.65 \pm 1.814 \\
3.25 \pm 1.410\end{array}$ & 2.990 & 0.008 \\
\hline
\end{tabular}

Based on Table 2, it can be seen that the mean pre-post intervention score in group 1 (sitz bath hydrotherapy) on the first day $(4.10 \pm 1.861)$ was lower than the infrared group 2 intervention (5.95 \pm 2.88). On the third day of the intervention, the average reduction in the pain scale in group $1(1.80 \pm 1.056)$ was lower than in group 2 (3.25 \pm 1.410).

The average score of pain reduction occurs significantly from day to day consecutively for three days in group 1 than group 2. It was proven that the two group interventions (sitz bath hydrotherapy and infrared therapy) were statistically significant in reducing pain after intervention until the third day. Cold sitz bath hydrotherapy has a significant effect $(p=$ $0.004)$ and infrared therapy (0.008). However, changes in the mean score of pain reduction indicate that sitz bath hydrotherapy is more significant in reducing pain than infrared therapy intervention.

\section{DISCUSSION}

Both of the interventions applied in this study, i.e., cold sitz bath hydrotherapy and infrared therapy did not show a statistical difference in reducing perineal wound pain in postpartum mothers' spontaneous birth. However, the study results prove that cold sitz bath hydrotherapy is better (1.80 \pm 1.05 ) in reducing the pain scale in postpartum wounds compared to infrared therapy $(3.25 \pm 1.41)$ for three consecutive days with levels significance $p=0.004$. This result differs from some of the effects of researchers that stated that infrared rays are more effective in reducing pain in perineal wounds (Balakrishnan \& Soman, 2019; El-Lassy, 2019; Dhanalakshmi, 2010; Venkadalakshmi et al., 2010).

Therapy, using the principle of hydrotherapy in the sitting position (sitz bath), has proven useful for recovery therapy. The principal application of hydrotherapy is to stimulate the circulation of the pelvic region. This hydrotherapy uses alternative cold water because it can overcome edema in perineal wounds compared to warm water (Tejirian \& Abbas, 2005). Analysis of pain scale scores using two-way analysis of variance with replication showed that sitz baths with cold water were significantly more effective in relieving perineal pain.

The literature search results stated that sitz bath hydrotherapy with cold water at temperatures of $55^{\circ}-75^{\circ} \mathrm{F}$ 
$\left(12^{\circ}-24^{\circ} \mathrm{C}\right)$ is useful in healing perineal wounds. Hydrotherapy with mean water results in a decrease in cell metabolism and a reduction in oxygen use around the tissues that are not injured. Some studies have also shown cold water therapy causes vasoconstriction and increases venous circulation. The occurrence of venous vasoconstriction can help the drainage process in edema tissue by the lymph vessels. After vasoconstriction in the edema tissue, the retained intracellular fluid will flow slowly through connective tissue between muscle fibers into the lymph channels. The drainage process is also facilitated by a pump that occurs due to muscle contraction and relaxation (Geytenbeek, 2002; McPhee, S. J., Papadakis, M. A., \& Rabow, 2010; Netter, 2017). Therefore, hydrotherapy with cold water in spontaneous postpartum mothers who experience perineal laceration can be one type of perineal wound management to treat perineal edema.

Infrared therapy is a treatment designed to avoid infection in perineal wounds. Infrared waves can help relieve pain, cure infections, and reduce inflammation. All the light waves produced are safe enough for all layers of the skin. The uppermost epidermal layer, then the dermis layer below, contains blood vessels and the tip that is very sensitive to the bottom subcutaneous fat tissue (Helen, 2009). Infrared lights improve circulation in those areas. Therefore, vasodilation occurs when the heat is applied to the wound's Episiotomy. Blood circulation to the areas increases - blood contains the nutrient oxygen (Gale et al., 2006; El-Lassy, 2019).

The process of decreasing the level of perineal wound pain with sitz bath hydrotherapy and infrared therapy is different. However, both of these interventions reduce the level of perineal wound pain. Chart 1 showed that the decrease in pain level in the cold sitz bath hydrotherapy intervention was more significant than the infrared therapy intervention. This result can be influenced by several sociodemographic factors, including age group, culture or ethnicity, and education level. The race is a background that shows differences in behavior, beliefs, culture, historical values, characteristics, and physical characteristics (Edwards et al., 2001). Ethnicity correlates with how someone behaves emotionally and how his behavior responds to the pain stimulus that occurs (Campbell \& Edwards, 2012). Both interventions in this study are interventions that can be easily carried out at home independently by the mothers, but there are still differences in pain reduction. Some of the factors sociodemographic characteristics and the culture, religion, and beliefs of each person can influence one's perception and experience in adapting to pain (Campbell \& Edwards, 2012).

\section{Limitation of the Study}

Respondents of this study were only 20 postpartum mothers, so it was quite limited in recording the social cultural characteristics as a whole in the place of research. This is a limitation in this study due to the Covid-19 pandemic situation, and limited time and research resources. This will be a benchmark for further research.

\section{CONCLUSION AND RECOMMENDATION}

This study's findings prove that cold sitz bath hydrotherapy and infrared therapy can significantly reduce pain intensity. However, on the third day, the infrared treatment did not significantly reduce the pain level. Compared to infrared therapy, the cold sitz bath hydrotherapy intervention procedure is more comfortable to carry out independently at home due to ease and economic value. This method can be recommended as a procedure for treating perineal wounds on the ward or at home.

\section{REFERENCES}

Balakrishnan, V., \& Soman, S. (2019). Effect of infrared light therapy on episiotomy pain and wound healing among postnatal mothers. International Journal of Science and Research, 8(3), 1543-1548.

Campbell, C. M., \& Edwards, R. R. (2012). Ethnic differences in pain and pain management. Pain Management, 2(3), 219-230. https://doi.org/10.2217/pmt.12.7

De Bernis, L., Sherratt, D. R., AbouZahr, C., \& Van Lerberghe, W. (2003). Skilled attendants for pregnancy, childbirth and postnatal care. British Medical Bulletin, 67, 39-57. https://doi.org/10.1093/bmb/ldg017

Dewi, V., \& Ayuningtyas, I. (2015). Infrared is more effective in perineum wound healing during postpartum than iodine. International Journal of Research in Medical Sciences, $3(1)$, S6-S9. https://doi.org/10.18203/2320-6012.jjrms20151513

Edwards, C. L., Fillingim, R. B., \& Keefe, F. (2001). Race, ethnicity and pain. Pain, 94(2), 133-137. https://doi.org/10.1016/S0304-3959(01)00408-0

Enkin, M., Keirse, M. J., Neilson, J., Crowther, C., Duley, L., Hodnett, E., \& Hofmeyr, G. J. (2001). Effective care in pregnancy and childbirth: a synopsis. Birth (Berkeley, $\quad$ Calif.), 28(1), 41-51. https://doi.org/10.1046/j.1523-536x.2001.00041.x

Gale, G. D., Rothbart, P. J., \& Li, Y. (2006). Infrared therapy for chronic low back pain: a randomized, controlled trial. Pain Research \& Management, 11(3), 193-196. https://doi.org/10.1155/2006/876920

Geytenbeek, J. (2002). Evidence for effective hydrotherapy. Physiotherapy, 88(9), 514-529. https://doi.org/10.1016/S0031-9406(05)60134-4

Helen. (2009). Keperawatan maternitas (maternity care) ( editor bahasa I. Y. asih alih bahasa Andry Hartono (ed.); 2nd ed.). Jakarta: EGC.

Hernawati, I. (2011). Analisis Kematian Ibu Di Indonesia Tahun 2010 (Analysis of Maternal Mortality in Indonesia, 2010). Bina Kesehatan Ibu Bakti Husada.

Horwitz, L. R., Burke, T. J., \& Carnegie, D. (1999). Augmentation of wound healing using monochromatic infrared energy. Exploration of a new technology for wound management. Advances in Wound Care: The Journal for Prevention and Healing, 12(1), 35-40.

Jacob, A., R, R., \& Tarachand, J. S. (2007). Clinical nursing procedures: The art of nursing practice (1st editio). Jaypee Brothers Medical Publishers (P) Ltd.

Kemenkes RI. (2013). Profil Kesehatan Indonesia Tahun 2012 (Indonesia Health Profile 2012). Kementerian Kesehatan Republik Indonesia.

Larsson, P. G., Platz-Christensen, J. J., Bergman, B., \& Wallstersson, G. (1991). Advantage or disadvantage of episiotomy compared with spontaneous perineal laceration. Gynecologic and Obstetric Investigation, 31(4), 213-216. https://doi.org/10.1159/000293161 
McPhee, S. J., Papadakis, M. A., \& Rabow, M. W. (2010). Current medical diagnosis \& treatment. New York: McGraw-Hill Medical.

Netter, F. H. (2017). Atlas of human anatomy, plate 46. Philadelphia, PA: Elsevier.

Ramler, D., \& Roberts, J. (1986). A comparison of cold and warm sitz baths for relief of postpartum perineal pain. Journal of Obstetric, Gynecologic, and Neonatal Nursing: JOGNN, 15(6), 471-474. https://doi.org/10.1111/j.1552-6909.1986.tb01426.x

Reem Bassiouny Mahmoud El-Lassy, A. A. E.-A. M. M. (2019). The effect of infrared lamp therapy on episiotomy wound restorative besides pain relief among post-partum women. Journal of Nursing Education and Practice, 9(2), 20-30.

Sleep, J., Robinson, S., \& Thompson, A. (1991). Midwives research and childbirth. Perineal Care: A Series of Five Randomised Trials, 2, 199-251.

Sule, S. T., \& Shittu, S. O. (2003). Puerperal complications of episiotomies at Ahmadu Bello University Teaching
Hospital, Zaria, Nigeria. East African Medical Journal, 80(7), 351-356. https://doi.org/10.4314/eamj.v80i7.8717

Tejirian, T., \& Abbas, M. A. (2005). Sitz bath: where is the evidence? Scientific basis of a common practice. Diseases of the Colon and Rectum, 48(12), 23362340. https://doi.org/10.1007/s10350-005-0085-x

V Dhanalakshmi. (2010). Best remedial measure after Episiotomy? Sitz? Or Infrared Light Therapy?bath. Nightingale Nursing Times, 5(12)(Mar), 6-12.

Venkadalakshmi, V., Venkatesan, L., \& Perdita, H. M. (2010). Effect of infrared therapy on episiotomy pain and wound healing in postnatal mothers. The Nursing Journal of India, 101(9), 212-214.

Yang, Y.-J., Xu, Y.-M., Chen, W.-C., Zhu, J.-H., Lu, J., \& Zhong, B.-L. (2017). Prevalence of pain and its socio-demographic and clinical correlates among heroin-dependent patients receiving methadone maintenance treatment. Scientific Reports, 7, 8840. https://doi.org/10.1038/s41598-017-09404-w 